\title{
A national-scale seasonal hydrological forecast system: development and evaluation over Britain
}

\author{
Victoria A. Bell ${ }^{1}$, Helen N. Davies ${ }^{1}$, Alison L. Kay ${ }^{1}$, Anca Brookshaw ${ }^{2,3}$, and Adam A. Scaife ${ }^{3,4}$ \\ ${ }^{1}$ Centre for Ecology \& Hydrology, Wallingford, Oxfordshire, OX10 8BB, UK \\ ${ }^{2}$ ECMWF, Shinfield Park, Reading, RG2 9AX, UK \\ ${ }^{3}$ Met Office Hadley Centre, FitzRoy Road, Exeter, Devon, EX1 3PB, UK \\ ${ }^{4}$ College of Engineering, Mathematics and Physical Sciences, University of Exeter, Exeter, EX4 4QF, UK \\ Correspondence to: Victoria A. Bell (vib@ceh.ac.uk)
}

Received: 16 March 2017 - Discussion started: 20 March 2017

Revised: 21 July 2017 - Accepted: 14 August 2017 - Published: 15 September 2017

\begin{abstract}
Skilful winter seasonal predictions for the North Atlantic circulation and northern Europe have now been demonstrated and the potential for seasonal hydrological forecasting in the UK is now being explored. One of the techniques being used combines seasonal rainfall forecasts provided by operational weather forecast systems with hydrological modelling tools to provide estimates of seasonal mean river flows up to a few months ahead.

The work presented here shows how spatial information contained in a distributed hydrological model typically requiring high-resolution (daily or better) rainfall data can be used to provide an initial condition for a much simpler forecast model tailored to use low-resolution monthly rainfall forecasts. Rainfall forecasts ("hindcasts") from the GloSea5 model (1996 to 2009) are used to provide the first assessment of skill in these national-scale flow forecasts. The skill in the combined modelling system is assessed for different seasons and regions of Britain, and compared to what might be achieved using other approaches such as use of an ensemble of historical rainfall in a hydrological model, or a simple flow persistence forecast. The analysis indicates that only limited forecast skill is achievable for Spring and Summer seasonal hydrological forecasts; however, Autumn and Winter flows can be reasonably well forecast using (ensemble mean) rainfall forecasts based on either GloSea5 forecasts or historical rainfall (the preferred type of forecast depends on the region). Flow forecasts using ensemble mean GloSea5 rainfall perform most consistently well across Britain, and provide the most skilful forecasts overall at the 3-month lead time. Much of the skill $(64 \%)$ in the 1-month ahead seasonal flow fore-
\end{abstract}

casts can be attributed to the hydrological initial condition (particularly in regions with a significant groundwater contribution to flows), whereas for the 3-month ahead lead time, GloSea5 forecasts account for $\sim 70 \%$ of the forecast skill (mostly in areas of high rainfall to the north and west) and only $30 \%$ of the skill arises from hydrological memory (typically groundwater-dominated areas). Given the high spatial heterogeneity in typical patterns of UK rainfall and evaporation, future development of skilful spatially distributed seasonal forecasts could lead to substantial improvements in seasonal flow forecast capability, potentially benefitting practitioners interested in predicting hydrological extremes, not only in the UK but also across Europe.

\section{Introduction}

A series of low-pressure systems crossing Britain in Winter 2015/2016 resulted in some of the most widespread and severe flooding witnessed in the UK, with several rivers in the north of Britain recording their highest ever flows and thousands of properties flooded (Centre for Ecology \& Hydrology 2016). Repairs to damaged homes, businesses and flood defences were required, and procedures for forecasting and mitigating the floods are understandably being examined. Until relatively recently, a lack of skill in seasonal weather forecasts in extratropical regions beyond a lead time of 1 month (Lavers et al., 2009; Arribas et al., 2011) discouraged the development of routine seasonal hydrological forecasts using a climate model output in Britain. However, 
the potential for seasonal hydrological forecasting in the UK is now being explored. Various seasonal forecast systems now provide skilful forecasts out to a few months ahead (e.g. MacLachlan et al., 2015; Athanasiadis et al., 2014), allowing for some form of skilful dynamical hydrological forecast. As well as using a climate model output, others are investigating statistical relationships between large-scale North Atlantic climate indices (such as the North Atlantic Oscillation, NAO) and seasonal rainfall or river flow anomalies (Lavers et al., 2010a, b; McGregor and Phillips, 2004; Svensson and Prudhomme, 2005; Wedgbrow et al., 2002; Wilby, 2001; Svensson et al., 2015), and these can provide increased skill when large-scale patterns dominate regional rainfall (Scaife et al., 2014).

A recent review of seasonal hydrological forecasting methods using a climate model output by Yuan et al. (2015) highlighted the dependence of predictive skill on both the large-scale climate drivers and the local hydrological initial condition (HIC), which for some regions can persist for several months. The relative importance of initial conditions and boundary forcing (the meteorological forecast) on the skill of seasonal hydrological prediction has been examined by a number of authors; for example, a study of skill in forecasting mean seasonal river flows across Europe concluded that much of the skill could be attributed to correct hydrological initial conditions, rather than the weather forecast (Bierkens and van Beek, 2009). In a UK-based study, also using seasonal forecasts, Svensson et al. (2015) identified a geographical complementarity in regional seasonal hydrological predictability, noting that predictability in river flows in southern and eastern Britain derived primarily from hydrological memory of antecedent conditions, and from meteorological predictability (predictions of the atmospheric circulation over the North Atlantic at the seasonal timescale) in northern and western areas. They were able to generate skilful hydrological forecasts for river flows using the large-scale atmospheric circulation which governs much of UK winter (December to February) rainfall, and November initial conditions.

Advances in the performance of operational seasonal forecast systems such as the Met Office's GloSea5 system (MacLachlan et al., 2015) are now encouraging the development of hydrological forecasting systems that can make best use of these more skilful seasonal forecasts. In the UK, the recently developed Hydrological Outlook UK (HOUK) provides an insight into future hydrological conditions nationwide. It describes likely trajectories for river flows and groundwater levels on a monthly basis, with particular focus on the next 1 and 3 months. A number of techniques are used to project forwards from the current state and results from these are used to produce a summary including a highlights map. Prudhomme et al. (2017) summarizes the range of techniques used in the production of the HOUK, which encompass schemes using historical river flow analogues, ensembles of historical sequences of observed cli- mate and ensembles of seasonal rainfall forecasts. The forecasts issued provide seasonal mean river flows and instantaneous groundwater levels with a forecast horizon of up to 12 months ahead, with an emphasis on the next 1 to 3 months (http://hydoutuk.net/).

The approach using seasonal rainfall forecasts provided by the Met Office's GloSea5 model is explored in more detail here. These rainfall forecasts are combined with hydrological modelling tools to provide estimates of hydrological conditions up to a few months ahead. The hydrological modelling follows on from an approach to seasonal forecasting developed by Bell et al. (2013), which used a distributed hydrological model driven by observations to provide the hydrological initial condition, and a monthly "water-balance anomaly" model to estimate subsurface water storage over the next 1 to 3 months as perturbations from the initial state, driven by Met Office seasonal rainfall forecasts. Forecasting UKwide monthly-mean river flow is less straightforward than forecasting subsurface water storage, as river flow is a spatial and temporal integrator of local-scale runoff production, arising from a combination of antecedent storage and the partitioning of effective rainfall between surface/subsurface runoff and storage. This task can arguably be undertaken by a fully configured grid-based hydrological model, maintaining a continuous local water-balance and using daily or subdaily spatial rainfall estimates as input. However, seasonal rainfall forecasts do not provide detailed weather information at this resolution and would typically require spatiotemporal downscaling to achieve good estimates of river flow for catchments or regions nationwide. While rainfall downscaling is relatively straightforward for a particular location or catchment, using national-scale monthly rainfall forecasts to produce pixel-scale daily rainfall would require an ensemble downscaling approach based on either a weather generator or historical analogues, generating large multiples of ensemble flow forecasts. This approach has been explored in other studies (e.g. Manzanas et al., 2017; Charles et al., 2012), which showed that dynamic or statistical downscaling of seasonal forecasts can reduce local biases in variables such as temperature or rainfall but do not necessarily improve the overall forecast skill.

The alternative approach explored here is to place the greatest emphasis on the hydrological initial condition provided by an up-to-date model, while simplifying the generation of hydrological forecasts through the use of a temporally coarse water-balance model with less dependence on highresolution weather information. A monthly-resolution forecast model provides additional benefits by reducing the computational overhead of the use of a rainfall forecast ensemble. This scheme is used to provide regional-scale estimates of the river flows over the coming months, and work presented here examines the skill of these forecasts for Britain, for geographical regions, for particular seasons, and at 1- and 3-month lead times. 


\section{Models and methods}

\subsection{Hydrological initial condition}

Grid-to-Grid (G2G) is a spatially distributed hydrological model, which is generally configured to a $1 \mathrm{~km}^{2}$ grid across Britain, with a 15 min time step and underpinned by digital spatial datasets of topography, soil geology and land cover. A detailed description of $\mathrm{G} 2 \mathrm{G}$ is presented in Bell et al. (2009), with a brief overview of the model's subsurface (soil and groundwater) storage formulation provided in Bell et al. (2013). Input to the model consists of gridded time series of precipitation and potential evaporation (PE) derived from observations, numerical weather prediction or regional climate models. Model output can be in the form of area-wide, gridded time series of river flows, runoff and soilmoisture, or time series of river flows at gauged or ungauged locations. Applications of the model include both continuous simulation of river flows in a changing climate (Bell et al., 2009, 2016) and real-time flood forecasting (Moore et al., 2006; Cole and Moore, 2009).

For production of the HOUK, G2G is run continuously over several years to produce an estimate of the most recent hydrological condition across Britain, from which an estimate is made of the current depth of subsurface water storage. The $\mathrm{G} 2 \mathrm{G}$ requires gridded time series of rainfall and PE. Daily precipitation data on a $5 \mathrm{~km}$ grid, provided by the Met Office for 1958-present (Perry et al., 2009), were used at the $15 \mathrm{~min}$ G2G time step by equally spreading them throughout the day, and downscaled to $1 \mathrm{~km}$ using a spatial weighting based on $1 \mathrm{~km}$ standard average annual rainfall data for 1961-1990 (Bell et al., 2007). Monthly PE data on a $40 \mathrm{~km}$ grid from MORECS (Hough and Jones, 1997) were spread equally through the month and applied equally to each $1 \mathrm{~km}$ box within each $40 \mathrm{~km}$ square. Here, the depth of subsurface water storage, $S$, consists of the sum of the unsaturated soil, $V$, and the groundwater, $V_{\mathrm{g}}$, storages. The depth of water in groundwater storage arises from the balance between recharge and groundwater outflow over long periods, and while it is unlikely to correspond directly to a groundwater level observation, it can provide an indication of whether storage in the saturated zone is greater or less than the longterm monthly average.

\subsection{Water-balance model for flows}

Following Bell et al. (2013) the continuity equation can be used to express the change in total subsurface water storage, $S$, as a balance between input precipitation $P$ and outputs through actual evaporation $E$ and net outflow per unit area $Q$, so $\mathrm{d} S / \mathrm{d} t=P-E-Q$, where all quantities are expressed in water depth $(\mathrm{mm})$ over a model grid-cell. In terms of discrete months, if $S_{\mathrm{m}}$ and $S_{\mathrm{m}+1}$ represent the storage at the end of months $m$ and $m+1$, and if $P_{\mathrm{m}+1}, E_{\mathrm{m}+1}$ and $Q_{\mathrm{m}+1}$ denote mean rainfall, evaporation and net outflow per unit area over the month $m+1$, then

$S_{\mathrm{m}+1} \cong S_{\mathrm{m}}+P_{\mathrm{m}+1}-E_{\mathrm{m}+1}-Q_{\mathrm{m}+1}$.

At a monthly time step it is assumed here that daily and subdaily changes in rainfall, storage and net outflows can be neglected and gross simplifying assumptions can be made as to whether excess effective rainfall is stored in the subsurface or released via runoff from saturated pixels. Storage of water in each pixel is assumed to vary between $S_{\min }$ and $S_{\max }$, the historical minimum and maximum G2G-simulated storage of each $1 \mathrm{~km}$ pixel's subsurface water store respectively. By combining the current storage $S_{\mathrm{m}}$ as estimated by the G2G at the forecast time origin with monthly seasonal forecasts of $P_{\mathrm{m}+1}$ and $E_{\mathrm{m}+1}$, corresponding forecasts of storage and flow can be produced as follows.

For a discrete month, $m$, an initial estimator of the storage in each pixel at the end of the following month $(m+1)$ can be given by

$\hat{S}_{\mathrm{m}+1}^{*} \approx S_{\mathrm{m}}+P_{\mathrm{f}}-E_{\mathrm{f}}$,

where $P_{\mathrm{f}}$ and $E_{\mathrm{f}}$ are seasonal forecasts of mean monthly rainfall and actual evaporation, and the * indicates an initial (as opposed to final) estimator.

The initial estimator for forecast storage $\hat{S}_{\mathrm{m}+1}^{*}$ (Eq. 2) neglects forecast $Q_{\mathrm{m}+1}$, which can be significant, but is less easy to forecast directly than storage as its magnitude will depend on a number of factors including soil properties, storage, effective rainfall and topography. Typically in hydrological models, river flow is estimated through a relationship between incoming effective rainfall and antecedent soilmoisture and subsurface water storage, and for the seasonal forecasting application considered here, $Q_{\mathrm{m}+1}$ is also estimated through a relationship of the form $Q \simeq f(S)$. For the national-scale application required for the HOUK encompassing a wide range of soils, geology and catchment characteristics, a very simple empirical relationship relating gridcell net outflow in a month to mean monthly river flow is assumed:

$\hat{Q}_{\mathrm{m}+1} \simeq \hat{S}_{\mathrm{m}+1}^{*} \frac{\bar{q}_{\mathrm{m}+1}}{\bar{S}_{\mathrm{m}+1}}$.

Here, mean monthly net outflow in month $m+1$ is estimated in terms of the forecast storage $\hat{S}_{\mathrm{m}+1}^{*}$ scaled by the ratio between $\mathrm{G} 2 \mathrm{G}$ model-derived estimates of long-term mean river flow per unit catchment area, $\bar{q}_{\mathrm{m}+1}$, and storage $\bar{S}_{\mathrm{m}+1}$ for the month (1962 to 2010).

Replacing the unknown $Q_{\mathrm{m}+1}$ in Eq. (1) with its estimator $\hat{Q}_{\mathrm{m}+1}$ yields an improved estimate of $S_{\mathrm{m}+1}$ : 


$$
\begin{aligned}
\hat{S}_{\mathrm{m}+1} & \approx\left(S_{\mathrm{m}}+P_{\mathrm{f}}-E_{\mathrm{f}}\right)\left(1-\frac{\bar{q}_{\mathrm{m}+1}}{\bar{S}_{\mathrm{m}+1}}\right) \\
& \approx \begin{cases}\hat{S}_{\mathrm{m}+1}^{*}\left(1-\frac{\bar{q}_{\mathrm{m}+1}}{\bar{S}_{\mathrm{m}+1}}\right), & \text { for } \frac{\bar{q}_{\mathrm{m}+1}}{\bar{S}_{\mathrm{m}+1}}<1 . \\
0, & \text { else }\end{cases}
\end{aligned}
$$

Equations (1), (3) and (4) form the basis of the water-balance model (WBM), which considers two situations according to whether the forecast subsurface storage in the pixel is saturated:

- For saturated pixels, defined as $\hat{S}_{\mathrm{m}+1} \geq S_{\mathrm{max}}$, further excess rainfall cannot be accommodated as subsurface storage and is instead assumed to contribute directly to surface runoff and river flows. Then storage at the end of the next month $S_{\mathrm{m}+1}=S_{\max }$ and, re-arranging Eq. (1), $Q_{\mathrm{m}+1} \approx S_{\mathrm{m}}+P_{\mathrm{f}}-E_{\mathrm{f}}-S_{\max }$.

- For unsaturated pixels, defined by $\hat{S}_{\mathrm{m}+1}<S_{\max }$, excess rainfall is assumed to contribute to both subsurface storage and net outflow, and forecasts of these variables are estimated from Eqs. (4) and (3) respectively. For a small number of locations in highly spatially variable catchments, where $\frac{\bar{q}_{\mathrm{m}+1}}{\bar{S}_{\mathrm{m}+1}} \geq 1$, to maintain continuity, $S_{\mathrm{m}+1}=0$ and $Q_{\mathrm{m}+1}=S_{\mathrm{m}}+P_{\mathrm{f}}-E_{\mathrm{f}}$.

Net outflow estimates $(\mathrm{mm})$ for each grid-square in each region are converted to monthly-mean river flows $\left(\mathrm{m}^{3} \mathrm{~s}^{-1}\right)$ through lateral transfer of upstream flows from each catchment to the catchment outlet for every river grid-cell, using the $1 \mathrm{~km}$ flow directions identified for the kinematic wave routing implemented in the G2G Model (Davies and Bell, 2008; Bell et al., 2009). WBM flows for every $1 \mathrm{~km}$ river location are scaled with respect to historical mean WBM flow (1962-2010) and these standardized flows are averaged to provide a mean value for each of the 17 geographic regions (Fig. 1b). The coarse spatial resolution of the input rainfall forecasts has discouraged the development of river flow forecasts at a $1 \mathrm{~km}$ resolution to ensure that users of the HOUK do not infer that rainfall forecasts are available or skilful at this resolution. Production of regional scale forecasts (in preference to national scale) is viewed as a pragmatic compromise.

\subsection{Seasonal rainfall forecasts}

The long-range meteorological forecasts used here were produced using the Met Office Global Seasonal forecast system (GloSea5; MacLachlan et al., 2015) and consist of a multimember ensemble of UK-averaged (i.e. spatially uniform) monthly total rainfall forecast for the next month, available at the start of each month. The climate model at the core of this forecast system has an atmospheric resolution of $0.83^{\circ}$ longitude by $0.55^{\circ}$ latitude, 85 quasi-horizontal atmospheric levels and an upper boundary at $85 \mathrm{~km}$ near the mesopause (a)

(b)

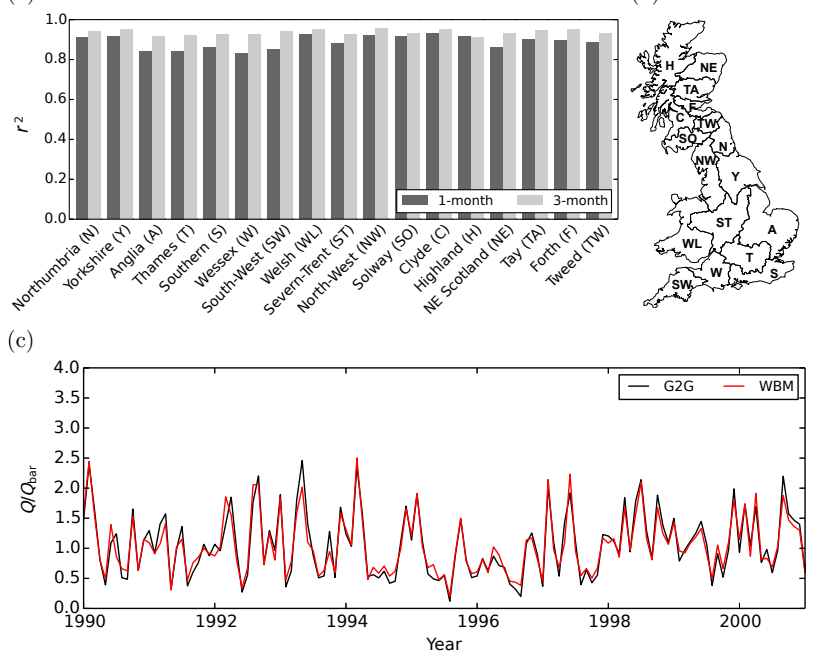

(d)

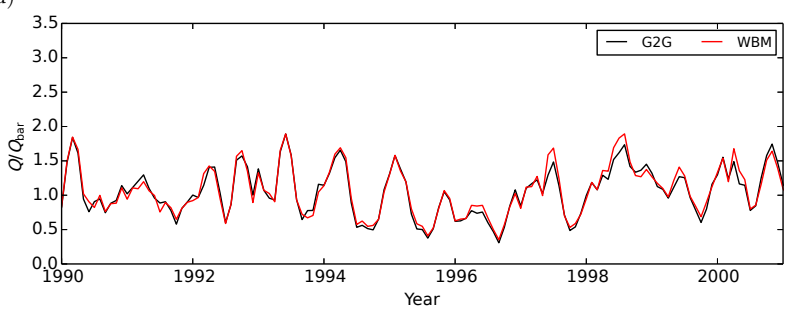

Figure 1. (a) Regional water-balance model (WBM) performance (1- and 3-months ahead) compared to G2G output for 17 regions, in terms of the (Pearson) $r^{2}$. The regions are shown in (b). Monthly time series of (c) 1-month and (d) 3-month ahead forecasts for the period January 1990 to December 2000 with mean G2G (black) and WBM (red) simulated flows for the Forth region.

to represent stratospheric processes which are important for winter forecasts (Scaife et al., 2016). The ocean resolution is $0.25^{\circ}$ globally in both latitude and longitude with 75 quasihorizontal levels. This ocean resolution is necessary to reduce key biases in the ocean and atmosphere and give a realistic winter atmospheric blocking climatology in the model (Scaife et al., 2011). A multi-member ensemble of 1- and 3 -month rainfall forecasts $\left(\mathrm{mm} \mathrm{day}^{-1}\right)$ was run for each season in the period 1996 to 2009 with lagged start dates centred on 1 February, 1 May, 1 August and 1 November. Also, 12 ensemble members were available for forecasts starting in August and February and 24 for those starting in May and November. Thus ensembles of 1-month ahead forecasts are provided for December, March, June and September, and 3-month ahead forecasts for Winter (DJF), Spring (MAM), Summer (JJA) and Autumn (SON). Members from the same start date differ only by stochastic physics. Initial atmospheric and land surface data were taken from ERA-Interim observational reanalyses and initial conditions for the global ocean and sea ice concentration were from the Forecast Ocean Assimilation Model (FOAM) data assimilation system (Blockley et al., 2014). 
The spatially uniform rainfall forecasts present a dilemma for hydrological modellers who typically require high spatial and temporal resolution weather information to estimate a water balance and represent the highly spatially and temporally variable nature of streamflow. An ensemble of mean UK rainfall forecasts provides no information on whether the rainfall is more likely to occur in the north or south, however, it does provide some indication of whether the rainfall totals will be higher or lower than the climatological (long-term) mean. Such spatially uniform forecasts will be unable to provide the spatial heterogeneity observed in UK rainfall and would under/overestimate rainfall in northern/southern regions if used directly. Instead, the rainfall forecasts $P_{\mathrm{f}}$ are converted to spatially uniform rainfall anomalies, $a=P_{\mathrm{f}}-\overline{P_{\mathrm{f}}}(\mathrm{mm})$ relative to the GloSea5 estimate of climatological mean rainfall $\left(\overline{P_{\mathrm{f}}}\right)$. A spatially distributed UK monthly rainfall amount, $P^{*}$, is then calculated as $P^{*}=\frac{P_{i j}}{\bar{P}}(\bar{P}+a)$, where $\bar{P}$ and $P_{i j}$ are the UK-mean and the local (1 km pixel) monthly-mean rainfall (1971-2000) respectively. This approach to spatial downscaling using historical mean rainfall observations is similar to one used by Bell et al. (2009) to downscale $25 \mathrm{~km}$ resolution regional climate model data to a $1 \mathrm{~km}$ resolution.

To produce the 3-month ahead flow forecasts using the GloSea5 hindcast dataset, either sequential monthly rainfall forecasts or a 3-month mean rainfall forecast were available for use as input, thus for Winter (DJF), forecasts were available for December, January and February separately and the 3-month (DJF) mean. In the analysis that follows, forecast skill has been assessed using both temporal resolutions of rainfall forecast, but as the results are very similar, only results for the mean 3-month ahead forecast are presented. This is consistent with the monthly HOUK for which forecasts at lead times of 1- and 3-months only are available. Disaggregation of the 3-month ahead forecast into monthly rainfall amounts is achieved through distributing the 3-month rainfall forecast anomaly between the 3 individual months according to their relative contribution to the UK-mean seasonal rainfall (1962 to 2010).

\subsection{Seasonal flow forecasts}

To produce seasonal flow forecasts (hindcasts), the waterbalance model for flows (Sect. 2.2) is initialized with the most recent $\mathrm{G} 2 \mathrm{G}$ estimate of subsurface water storage (Sect. 2.1). GloSea5 seasonal rainfall forecasts (1- and 3months ahead, Sect. 2.3) are applied alongside climatological monthly mean actual evaporation (AE) estimated from a long G2G model run (1962 to 2010).

While the skill of a single set of forecasts can be compared to observations using measures such as the Pearson correlation coefficient, the performance of an ensemble of seasonal flow forecasts can more easily be assessed using the relative operating characteristic (ROC) skill score (Kharin and Zwiers, 2003), used widely for probabilistic weather forecast verification. For ensembles, the ROC is a curve that indicates the relationship between hit rate and false alarm rate as different sorted ensemble members are used as decision thresholds. The ROC is commonly summarized through the integrated area under the curve, AUC, using $S_{\mathrm{ROC}}=2 \cdot \mathrm{AUC}-1$ : a perfect forecast has $S_{\mathrm{ROC}}=1$ $(\mathrm{AUC}=1.0)$, while forecasts with no skill have $S_{\mathrm{ROC}} \leq 0$ $($ AUC $\leq 0.5)$. The scores are calculated separately for each of the three severity bands (below normal, 0-28\%; normal, 28-72\%; above normal, 72-100\%), by ranking standardized river flow forecasts for the 17 geographical regions of Britain in relation to simplified percentile ranges of historical flow estimates for each month based on 49 years of WBM simulated flows (1962-2010). The relatively wide bands were selected to agree with that used by both the rest of the HOUK methods and by the Hydrological Summary produced by the National Hydrological Monitoring Programme (Dixon et al., 2013), and serve to highlight when flows are unusually high or low.

To assess the importance of various factors involved in the seasonal flow forecasts, the performance of four alternatives is compared:

a. WBM with GloSea5 rainfall forecasts and the most recent G2G HIC ("GloSea5 + HIC"),

b. WBM with GloSea5 rainfall forecasts and a G2G historical mean HIC (1962-2010) (“GloSea5 + avHIC"),

c. WBM with an historical observed (spatially averaged) rainfall ensemble (49 members, 1962-2010) and the G2G HIC ("Hist + HIC") and

\section{d. flow persistence with the G2G HIC ("Pers").}

Comparing (b) to (a) gives an idea of the relative contribution of HIC to forecast skill, while comparing (c) to (a) gives an idea of the relative contribution of GloSea5 rainfall to forecast skill. Flow persistence (d) (carrying the most recent flow anomaly forward to the next 1 - and 3-months) provides a much simpler form of forecast, for overall comparison. The skill of WBM with the G2G historical mean HIC and the ensemble of historical observed rainfall was also assessed but, as would be expected, the ensemble of forecasts had zero skill $\left(S_{\mathrm{ROC}}=0\right)$ and for brevity have been excluded from the analysis. Performance results for the remaining four alternatives are presented in Sect. 3.2.

\section{Results}

\subsection{Assessment of the water-balance model for flows}

The performance of the WBM to produce flow forecasts was assessed on a regional scale for the period January 1962 to December 2010 using observed gridded rainfall inputs (i.e. assuming a perfect rainfall forecast) and monthly mean 
AE (1962-2010) from the G2G, and initialising the WBM each month with the most recent G2G HIC. The resulting output, consisting of a temporal sequence of fixed lead time, 1- and 3-month ahead regional flow forecasts, was compared to $\mathrm{G} 2 \mathrm{G}$ regional mean monthly flows derived from a continuous simulation from 1962-2010 driven by observed (spatially distributed) daily $5 \mathrm{~km}$ gridded rainfall observations and MORECS PE as input (described in Sect. 2.1). A comparison with measured river flows at individual sites across Britain has not been undertaken because the WBM has been developed to provide regional monthly flows, and observed mean flows are not available on a regional scale.

Figure 1a provides a summary of WBM forecast performance in terms of the (Pearson) $r^{2}$ at the regional scale when compared to G2G output. For all 17 regions, the 1-month ahead WBM simulates more than $80 \%$ of the variability in G2G flows, and for 8 regions (typically upland regions highly responsive to rainfall), it explains more than $90 \%$. The 3month ahead forecasts all explain more than $90 \%$ of the variability. By way of example, Fig. 1c and d show modelled regional mean river flows for the Forth region (which has the median model performance for the 1-month lead time), illustrating how closely the 1- and 3-month ahead WBM forecasts match continuous simulation $\mathrm{G} 2 \mathrm{G}$ regional mean flows. Regional flows are estimated as the regional mean of $Q / \bar{Q}$ at every location $\left(1 \mathrm{~km}\right.$ pixel) for which $\bar{Q}>0.05 \mathrm{~m}^{3} \mathrm{~s}^{-1}$. The division by $\bar{Q}$ enables equal weighting for upstream and downstream river locations.

\subsection{Assessment of seasonal flow forecasts}

An assessment of model skill using the $S_{\text {ROC }}$ skill score has been undertaken for Britain as a whole, for 17 regions, two lead times and four forecast starting points (seasons). A skill assessment should ideally take into account all these factors, and although the average performance measure over all areas shown in Fig. 2a disguises the complexity in regional response and forecast model performance at different times of year, it does immediately highlight the utility of using the HIC with rainfall ensembles (GloSea5 or historical) over use of an average HIC or flow persistence. It is important to note that although skill scores improve with the number of ensemble members (Scaife et al., 2014), for the skill assessments here, the ensemble size varies: the historical rainfall ensemble has 49 members, while the rainfall forecast ensemble has 12 or 24 members for autumn/summer and summer/winter, respectively. Thus, the forecast rainfall skill scores may be an underestimate of the real-time skill (operational GloSea5 forecasts have 42 members). At the 1-month lead time the WBM with G2G HIC driven by an historical rainfall (climatology) ensemble performs best, and the forecasts based on persistence or GloSea5 + HIC perform less well, but show some skill. For the longer 3-month lead time, the WBM with G2G HIC driven by either historical or GloSea5 rainfall per-

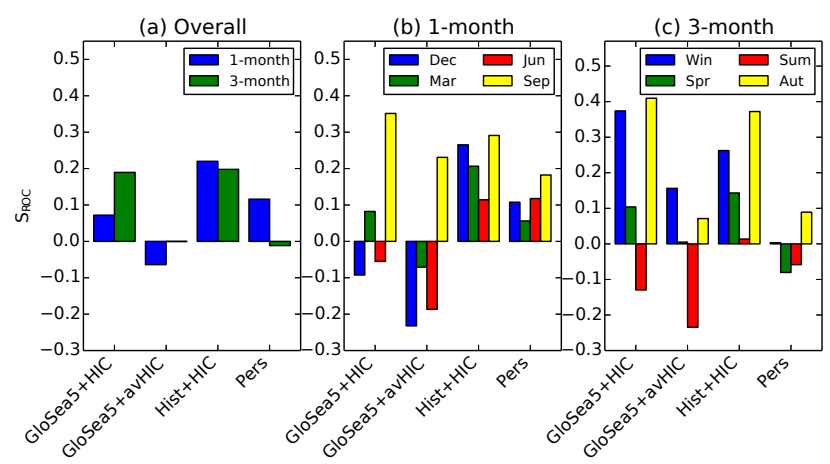

Figure 2. Bar charts showing $S_{\text {ROC }}$ (a) averaged across three severity bands, four seasons and 17 regions, at two forecast lead times (1 and 3 months). Panels (b, c) as (a) but presenting results for the four months/seasons separately at the two forecast lead times.

form similarly; persistence forecasts (Pers) or use of an average HIC are not recommended at this lead time.

When the overall performance scores shown in Fig. 2a are split between seasons, the utility of GloSea5 forecasts in September/Autumn and December/Winter becomes apparent (Fig. 2b and c; GloSea5 + HIC). For forecasts that use the HIC, use of an ensemble of historical rainfall provides some skill $\left(S_{R O C}>0\right)$ across all seasons, particularly at the 1-month lead time, but use of GloSea5 rainfall forecasts is more skilful in autumn (yellow bars) and also in winter (blue bars) at the 3-month lead time. There is little skill in summer flow forecasts (red bars) whatever type of rainfall forecasts is used, with the best 1-month ahead forecast performance achieved using historical rainfall, and best 3-month ahead forecasts from persistence of current flow conditions or historical rainfall. Scaife et al. (2016) identify several mechanisms as to why extratropical seasonal forecast skill is most apparent in winter, and thus less apparent in summer months. Seasonal forecasts of flows in Spring have only modest skill and use of historical rainfall and the HIC is recommended at both lead times.

Svensson et al. (2015) and Svensson (2016) highlight the value of a flow persistence forecast in southern and eastern regions of Britain in catchments with a high subsurface aquifer storage component and for which river flows respond slowly to rainfall. Here, analysing the ensemble results for each of the 17 regions, the skill of a flow persistence forecast in southern and eastern areas is apparent, but using a rainfall forecast ensemble (historical or GloSea5) and the most recent HIC is more skilful. The $S_{\text {ROC }}$ skill scores for each of the 17 regions (Fig. 3), indicate that skill (averaged over all seasons) is greatly dependent on the geographical region, with the historical rainfall ensemble with a HIC providing the best forecast in most regions, although at the 3-month lead time, a GloSea5 forecast ensemble with the HIC performs well. 

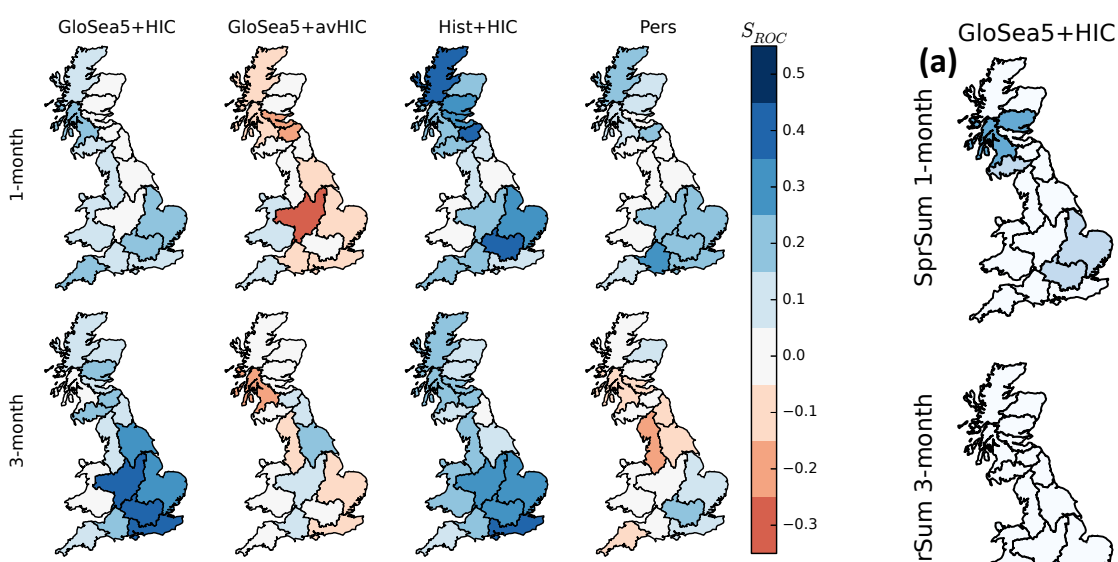

Figure 3. UK regional maps showing mean forecast skill for 17 regions and 2 lead times in terms of the $S_{\text {ROC }}$ ensemble skill score (higher skill shown in blue).

Although an ensemble of climate forecasts can provide some indication of the range of possible rainfall totals over the next few months, ensembles of seasonal climate predictions have been shown to possess a low ratio of predictable signal to unpredictable noise (Kumar, 2009; Eade et al., 2014; Scaife et al., 2014). These authors indicate that a single ensemble mean forecast can have greater skill than that of the constituent ensemble members, and Murphy (1990) provides a quantification of the apparent improvement in skill through its reduction in initial state uncertainty. More recently, Eade et al. (2014) suggest that improvements in forecast skill could be achieved by using the mean of a large ensemble, followed by a post-processing step to adjust the ensemble mean so its variance agrees with the predictable component of the observed variance. Svensson et al. (2015) restricted their UK-wide analysis of methods for winter flow forecasts to ensemble mean forecasts (3-months ahead) from GloSea5 and rainfall climatology together with a persistence forecast and found that skilful long-range forecasts of winter flows could be achieved through a combination of the hydrogeological memory of antecedent conditions in southern and eastern parts of the UK, and from meteorological predictability in northern and western areas. Here, it has not been possible to include the effect of the NAO index that was used by Svensson et al. (2015) alongside the GloSea5 winter forecasts, but the skill of ensemble mean GloSea5 rainfall forecasts has been evaluated for all seasons (not just winter). Results as Pearson correlation $(r)$ are summarised for UK regions in Fig. 4 for both Spring and Summer (labelled "SprSum") and Autumn and Winter ("AutWin"). The forecast methods used are labelled as in Fig. 3 but for GloSea5 and Historical rainfall forecast ensembles, only the ensemble mean forecast is used.

The difference in forecast skill between the seasons is immediately apparent, with a significant level of skill achieved
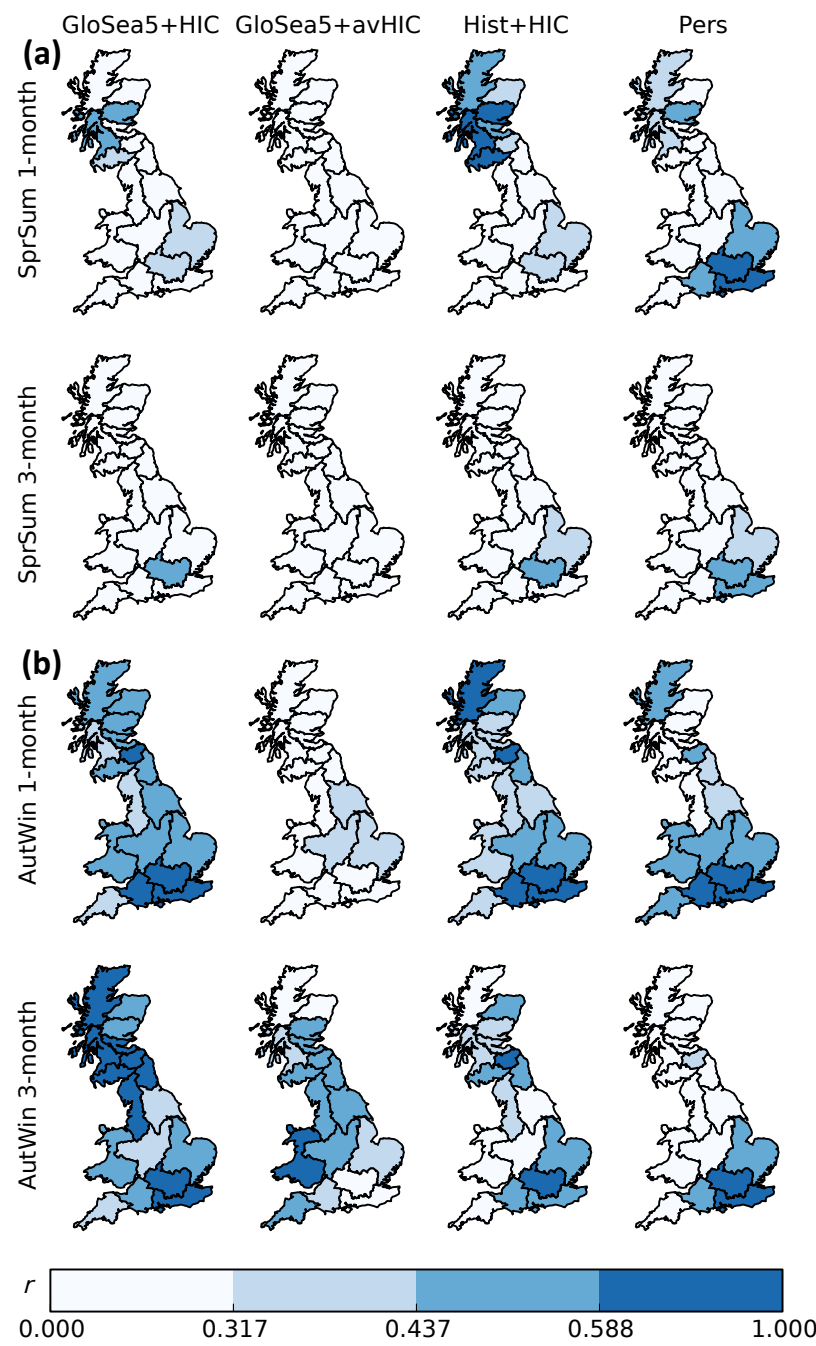

Figure 4. Maps showing 1- and 3-month ahead forecast skill (correlation $r$ ) for Spring/Summer (a) and Autumn/Winter (b). Thresholds are shown for $r<0.317$ (not significant); $0.317<r<0.437$ (significant at $5 \%$ level); $0.437<r<0.588$ (significant at $1 \%$ level) and $r>0.588$ (significant at $0.05 \%$ level).

for Autumn/Winter forecasts in many parts of Britain by including GloSea5 seasonal dynamical rainfall predictions:

- For Spring/Summer hydrological forecasts, some skill (at the 1\% significance level in the west of Scotland) is afforded through the use of a mean historical rainfall forecast in Scotland (1-month ahead only) and southeast regions (1- and 3-months ahead), however none of the methods tested is able to provide skilful seasonal forecasts of Spring/Summer flows in northern and western England or Wales. Across Britain as a whole, only the use of a mean historical rainfall forecast for a 1-month ahead flow forecasts shows any significant skill (mean correlation of 0.33 , significant at the $5 \%$ level). 
- By comparison, Autumn/Winter flows can be reasonably well forecast across Britain using ensemble mean rainfall forecasts based on GloSea5 or historical rainfall, with mean correlations of 0.53 and 0.50 respectively for 1-month ahead forecasts and 0.59 and 0.43 for 3 -months ahead. Forecasts using historical rainfall perform better at the 1-month ahead lead time than at 3months ahead, and again, skill is greater in Scotland and southeast Britain than in Wales and northern Britain.

The use of an average HIC with Spring/Summer rainfall forecasts from GloSea5 leads to forecasts with no significant skill, as it removes the main component of forecast skill which in Spring/Summer is associated with hydrological persistence. However, Autumn/Winter flow forecasts using ensemble mean GloSea5 rainfall and an average HIC perform surprisingly well across Britain, confirming that there is a significant element of skill associated with GloSea5 forecasts in Autumn/Winter at the 3-month lead time, often resulting in skilful flow forecasts in regions where this skill is less dependent on a good HIC.

By comparing forecast skill scores from different model configurations, it becomes possible to attribute overall forecast skill to the different model components such as HIC, GloSea5 ensemble and GloSea5 ensemble mean. Figure 5 provides an indication of the source of the forecast skill in Autumn/Winter for each region, alongside critical values for significance levels of Pearson's $r$ (5, 1 and $0.05 \%$ for a one-tailed test). For each region, the HIC skill is assumed to be the difference between the forecast skill for GloSea5 with HIC and with the long-term mean HIC ("avHIC"). Any GloSea5 skill beyond that associated with HIC can then be attributed to either the mean skill of the individual ensemble members or to the ensemble mean forecast (if they are greater than the HIC skill).

At the 1-month ahead lead time, the skill of Autumn/Winter GloSea5-derived forecasts in regions with longterm memory in the southeast (Thames, Southern, Wessex) and Scotland (Highland, NE Scotland, Tweed) is primarily attributable to the dependence of the flows on the antecedent conditions provided by the HIC (blue bars in Fig. 5). Averaged across all regions, the largest source $(64 \%)$ of skill in the 1-month ahead seasonal flow forecasts comes from the hydrological initial condition. This component of skill is also key to the success of the historical rainfall and persistence forecasts in Autumn/Winter. In many regions, particularly northern and western areas (Northumbria, Yorkshire, South-West, Welsh, North-West, Solway, Clyde, Forth and Tweed) a further 20 to $30 \%$ increase in skill arises from the GloSea5 ensemble mean (grey bars), and for a few regions (e.g. Anglia, Severn-Trent, Clyde) modest skill (10 to 20\%) is derived from the mean skill of the individual ensemble members (red bars). At the 3-month ahead lead time, the influence of the HIC on forecast skill is less apparent, and only 4 regions have levels of HIC-related skill significant at the
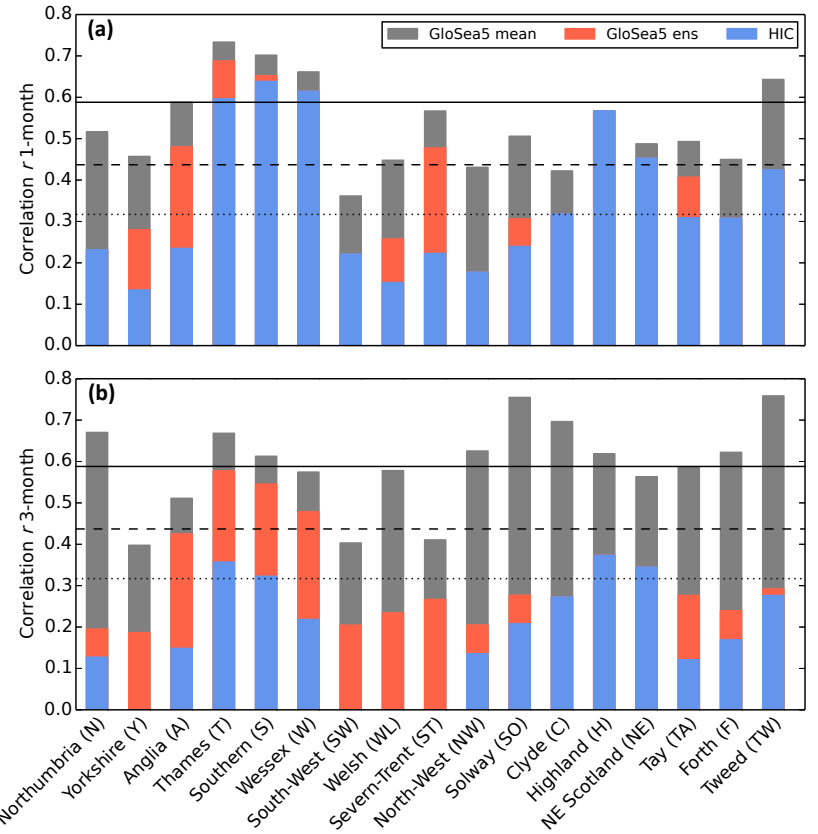

Figure 5. Sources of flow forecast skill (Pearson's $r$ ) in Autumn/Winter: (a) 1-month ahead and (b) 3-months ahead. Significance levels are shown with black horizontal lines (see Fig. 4). A map showing regions geographically is provided in Fig. $1 \mathrm{~b}$.

$5 \%$ level. Averaged across all regions, the HIC contributes to only a modest $30 \%$ of the forecast skill, whereas GloSea5 forecasts account for $\sim 70 \%$ of the forecast skill, of which $46 \%$ comes from mean ensemble skill and $23 \%$ from the mean skill of the individual ensemble members. This confirms the findings of Sect. 3.2 (Fig. 2) that indicated that at the 3-month lead time, an ensemble of GloSea5 forecasts and a good HIC performs well. A similar analysis of the source of skill in Spring/Summer forecasts (not shown here) indicates that almost all the skill in the forecasts comes from the HIC, with little skill arising from the GloSea5 rainfall forecasts (Fig. 2 indicates that an historical rainfall ensemble would be a better choice in Spring and Summer).

\section{Summary and recommendations}

The Hydrological Outlook UK (HOUK, Prudhomme et al., 2017) provides an insight into future hydrological conditions nationwide across Britain. It uses a range of techniques to provide likely trajectories for seasonal mean river flows and instantaneous groundwater levels on a monthly basis, with particular focus on the next 1 and 3 months. One of the techniques uses ensembles of UK-mean, monthly resolution seasonal rainfall forecasts provided by the Met Office's GloSea5 model with hydrological modelling tools. The approach combines a high-resolution, spatially distributed hydrological initial condition provided by a hydrological model 
(G2G) driven by weather observations up to the forecast time origin, with a monthly resolution WBM to forecast regional mean river flows for the next 1 and 3 months ahead.

The forecast skill of these regional-scale estimates of the river flows has been assessed for Britain, with results broken down between geographical regions, seasons, and at 1and 3-month lead times. Every month, the whole ensemble of rainfall forecasts is used in the operational HOUK to provide a range (median and four quartiles) of seasonal forecast flows over the next few months. However, recent literature (discussed in Sect. 3.2) suggests that ensembles of seasonal climate predictions can have such a low ratio of predictable signal to unpredictable noise that the ensemble mean forecast has much greater skill than the constituent ensemble members. Here, forecast skill has been assessed using both the whole rainfall ensemble and the ensemble mean. By comparing forecast skill scores from different model configurations, it has been possible to attribute overall forecast skill to the different model components such as HIC, GloSea5 ensemble and GloSea5 ensemble mean.

The analysis indicates that only limited forecast skill is achievable for Spring/Summer hydrological forecasts (through the use of historical rainfall rather than rainfall forecasts), however, Autumn/Winter flows can be reasonably well forecast across Britain using ensemble mean rainfall forecasts based on either GloSea5 forecasts or historical rainfall (the preferred type of forecast depends on the region). Flow forecasts using ensemble mean GloSea5 rainfall perform most consistently well across Britain, and provide the most skilful forecasts overall at the 3-month lead time. Most of the skill $(64 \%)$ in the 1-month ahead seasonal flow forecasts can be attributed to the hydrological initial condition, whereas for the 3-month ahead lead time, GloSea5 forecasts account for $\sim 70 \%$ of the forecast skill.

Svensson et al. (2015) highlighted that skilful seasonal predictions of UK river flows are "now a viable proposition" provided by the HOUK every calendar month on a national scale from (http://hydoutuk.net/). Currently, the whole ( 42 member) ensemble of GloSea5 rainfall forecasts is used to provide a range (median and four quartiles) of seasonal forecast flows over the next few months. The enhanced level of skill that can be achieved through the use of the ensemble mean forecast alone is an important consideration, but in practice this will be very close to the ensemble median already presented alongside the minimum, maximum and mid-quartile seasonal flow forecasts. Continued presentation of this full range of flow scenarios for the coming 1- and 3-months may be advantageous in that it informs water managers, not only of the most likely possibility but also to the range of possibilities. Based on the skill analysis presented here, users of the HOUK would be advised to have greatest confidence in Autumn and Winter flow forecasts that use GloSea5 rainfall, particularly at the 3-month lead time. For Spring and Summer flow forecasts, use of an ensemble forecast based on historical rainfall is surpris- ingly good and would be recommended for use across Scotland, and flow forecasts based on persistence were found to be the most skilful in south-east regions (Thames, Anglia, Wessex and Southern). The HOUK has been in operation for 4 years (publicly available from Autumn 2013) and thus is a relatively new product. At present, automated web statistics indicate approximately 300 readers or users of the HOUK website per month (Prudhomme et al., 2017). Exactly how water managers use the HOUK in practice has not yet been assessed, but ongoing evaluations of the skill in the different methods used in the construction of the outlook will undoubtedly help provide the evidence required to support use of the product in decision-making.

Despite the relatively low temporal and spatial resolution of the GloSea5 UK rainfall forecasts (currently at a monthly time step and national-scale), they can be used to provide skilful flow forecasts on a regional and national scale when combined with a hydrological-model-simulated estimate of the HIC. Given the high spatial heterogeneity in typical patterns of UK rainfall and evaporation, future development of higher resolution seasonal forecasts could lead to substantial improvements in seasonal flow forecast capability, benefitting practitioners interested in predicting flooding and water resources, not only in the UK but potentially across Europe.

Data availability. Met Office gridded rainfall and MORECS PE datasets are available from the Met Office (http://www.metoffice. gov.uk/services/data-provision). Daily river-flow data are available from the NRFA (http://nrfa.ceh.ac.uk/), and output from the HOUK and details of underlying methods are available on the HOUK website (http://www.hydoutuk.net/).

Competing interests. The authors declare that they have no conflict of interest.

Special issue statement. This article is part of the special issue "Sub-seasonal to seasonal hydrological forecasting". It is a result of the HEPEX workshop on seasonal hydrological forecasting, Norrköping, Sweden, 21-23 September 2015.

Acknowledgements. This work was funded by the NERC/CEH Water and Pollution Science Programme. AS was supported by the joint DECC/Defra Met Office Hadley Centre Climate Programme (GA01101), the UK Public Weather Service research programme.

Edited by: Andy Wood

Reviewed by: two anonymous referees 


\section{References}

Arribas, A., Glover, M., Maidens, A., Peterson, K., Gordon, M., MacLachlan, C., Graham, R., Fereday, D., Camp, J., Scaife, A. A., Xavier, P., McLean, A., Colman, A., and Cusack, S.: The GloSea4 ensemble prediction system for seasonal forecasting, Mon. Weather Rev., 139, 1891-1910, 2011.

Athanasiadis, P., Bellucci, A., Hermanson, L., Scaife, A. A., MacLachlan, C., Arribas, A., Materia, S., Borrelli, A., and Gualdi, S.: The representation of atmospheric blocking and the associated low frequency variability in two seasonal prediction systems, J. Climate, 27, 9082-9100, 2014.

Bell, V. A., Kay, A. L., Jones, R. G., and Moore, R. J.: Development of a high resolution grid-based river flow model for use with regional climate model output, Hydrol. Earth Syst. Sci., 11, 532-549, https://doi.org/10.5194/hess-11-532-2007, 2007.

Bell, V. A., Kay, A. L., Jones, R. G., Moore, R. J., and Reynard, N. S.: Use of soil data in a grid-based hydrological model to estimate spatial variation in changing flood risk across the UK, J. Hydrol., 377, 335-350, 2009.

Bell, V. A., Davies, H. N., Kay, A. L., Marsh, T. J., Brookshaw, A., and Jenkins, A.: Developing a large-scale water-balance approach to seasonal forecasting: application to the 2012 drought in Britain, Hydrol. Process., 27, 3003-3012, 2013.

Bell, V. A., Kay, A. L., Davies, H. N., and Jones, R. G.: An assessment of the possible impacts of climate change on snow and peak river flows across Britain, Climatic Change, 136, 539-553, 2016.

Bierkens, M. F. P. and van Beek L. P. H.: Seasonal predictability of European discharge: NAO and hydrological response time, J. Hydrometeorol., 10, 953-968, 2009.

Blockley, E. W., Martin, M. J., McLaren, A. J., Ryan, A. G., Waters, J., Lea, D. J., Mirouze, I., Peterson, K. A., Sellar, A., and Storkey, D.: Recent development of the Met Office operational ocean forecasting system: an overview and assessment of the new Global FOAM forecasts. Geosci. Model Dev., 7, 2613-2638, https://doi.org/10.5194/gmd-7-2613-2014, 2014.

Centre for Ecology \& Hydrology 2016, Hydrological Summary for the United Kingdom: December 2015, Centre for Ecology \& Hydrology, Wallingford, UK, 12 pp., 2016.

Charles, A., Timbal, B., Fernandez, E., and Hendon, H.: Analog downscaling of seasonal rainfall forecasts in the Murray Darling basin, Mon. Weather Rev., 141, 1099-1117, 2012.

Cole, S. J. and Moore, R. J.: Distributed hydrological modelling using weather radar in gauged and ungauged basins, Adv. Water Resour., 32, 1107-1120, 2009.

Davies, H. and Bell, V.: Assessment of methods for extracting low resolution river networks from high resolution digital data, Hydrolog. Sci. J., 54, 17-28, 2008.

Dixon, H., Hannaford, J., and Fry, M. J.: The effective management of national hydrometric data: Experiences from the United Kingdom, Hydrolog. Sci. J., 58, 1383-1399, 2013.

Eade, R., Smith, D., Scaife, A. A., Wallace, E., Dunstone, N., Hermanson, L., and Robinson, N.: Do seasonal-to-decadal climate predictions underestimate the predictability of the real world?, Geophys. Res. Lett., 41, 5620-5628, 2014.

Hough, M. N. and Jones, R. J. A.: The United Kingdom Meteorological Office rainfall and evaporation calculation system: MORECS version 2.0 - an overview, Hydrol. Earth Syst. Sci., 1, 227-239, https://doi.org/10.5194/hess-1-227-1997, 1997.
Kharin, V. V. and Zwiers, F. W.: On the ROC Score of Probability Forecasts, J. Climate, 16, 4145-4150, 2003.

Kumar, A.: Finite Samples and Uncertainty Estimates for Skill Measures for Seasonal Prediction, Mon. Weather Rev., 137, 2622-2631, 2009.

Lavers, D., Luo, L., and Wood, E. F.: A multiple model assessment of seasonal climate forecast skill for applications, Geophys. Res. Lett., 36, L23711, https://doi.org/10.1029/2009GL041365, 2009.

Lavers, D. A., Prudhomme, C., and Hannah, D. M.: Large-scale climate, precipitation and British river flows: identifying hydroclimatological connections and dynamics, J. Hydrol., 395, 242 255, 2010a.

Lavers, D. A., Prudhomme, C., and Hannah, D. M.: Large-scale climatic influences on precipitation and discharge for a British river basin, Hydrol. Process., 24, 2555-2563, 2010b.

MacLachlan, C., Arribas, A., Peterson, K. A., Maidens, A., Fereday, D., Scaife, A. A., Gordon, M., Vellinga, M., Williams, A., Comer, R. E., Camp, J., and Xavier, P.: Description of GloSea5: the Met Office high resolution seasonal forecast system, Q. J. Roy. Meteorol. Soc., 141, 1072-1084, 2015.

Manzanas, R., Gutiérrez, J. M., Fernández, J., van Meijgaard, E., Calmanti, S., Magariño, M. E., Cofiño, A. S., and Herrera, S.: Dynamical and statistical downscaling of seasonal temperature forecasts in Europe: Added value for user applications, Climate Services, https://doi.org/10.1016/j.cliser.2017.06.004, in press, 2017.

McGregor, G. R. and Phillips, I. D.: Specification and prediction of monthly and seasonal rainfall over the south-west peninsula of England, Q. J. Roy. Meteorol. Soc., 130, 193-210, 2004.

Moore, R. J., Cole, S. J., Bell, V. A., and Jones, D. A.: Issues in flood forecasting: ungauged basins, extreme floods and uncertainty, in: IAHS Publ. 305, Frontiers in Flood Research, edited by: Tchiguirinskaia, I., Thein, K. N. N., and Hubert, P., 8th Kovacs Colloquium, June/July 2006, UNESCO, Paris, 103-122, 2006.

Murphy, J. M.: Assessment of the practical utility of extended range ensemble forecasts, Q. J. Roy. Meteorol. Soc., 116, 89-125, 1990.

Perry, M., Hollis, D., and Elms, M.: The generation of daily gridded datasets of temperature and rainfall for the UK, Climate memorandum No. 24, UK Met Office, Exeter, UK, 2009.

Prudhomme, C., Hannaford, J., Boorman, D., Knight, J., Bell, V., Jackson, C., Svensson, C., Parry, S., Bachiller-Jareno, N., Davies, H. N., Davis, R., Harrigan, S., Mackay, J., Mackenzie, A., Rudd, A. C., Smith, K., Ward, R., and Jenkins, A.: Hydrological Outlook UK: an operational streamflow and groundwater level forecasting system at monthly to seasonal time scales, in review, 2017.

Scaife, A. A., Copsey, D., Gordon, C., Harris, C., Hinton, T., Keeley, S., O'Neill, A., Roberts, M., and Williams, K.: Improved Atlantic winter blocking in a climate model, Geophys. Res. Lett., 38, L23703, https://doi.org/10.1029/2011GL049573, 2011.

Scaife, A. A., Arribas, A., Blockley, E., Brookshaw, A., Clark, R. T., Dunstone, N., Eade, R., Fereday, D., Folland, C. K., Gordon, M., Hermanson, L., Knight, J. R., Lea, D. J., Maclachlan, C., Maidens, A., Martin, M., Peterson, A. K., Smith, D., Vellinga, M., Wallace, E., Waters, J., and Williams, A.: Skillful long-range prediction of European and North American winters, Geophys. Res. Lett., 41, 2514-2519, 2014. 
Scaife, A. A., Karpechko, A. Y., Baldwin, M. P., Brookshaw, A., Butler, A. H., Eade, R., Gordon, M., MacLachlan, C., Martin, N., Dunstone, N., and Smith, D.: Seasonal winter forecasts and the stratosphere, Atmos. Sci. Lett., 17, 51-56, 2016.

Svensson, C.: Seasonal river flow forecasts for the United Kingdom using persistence and historical analogues, Hydrolog. Sci. J., 61, 19-35, 2016.

Svensson, C. and Prudhomme, C.: Prediction of British summer river flows using winter predictors, Theor. Appl. Climatol., 82, $1-15,2005$.

Svensson, C., Brookshaw, A., Scaife, A. A., Bell, V. A., Mackay, J. D., Jackson, C. R., Hannaford, J., Davies, H. N., Arribas, A., and Stanley, S.: Long-range forecasts of UK winter hydrology, Environ. Res. Lett., 10, 064006, https://doi.org/10.1088/17489326/10/6/064006, 2015.
Wedgbrow, C. S., Wilby, R. L., Fox, H. R., and O'Hare, G.: Prospects for seasonal forecasting of summer drought and low river flow anomalies in England and Wales, Int. J. Climatol., 22, 219-236, 2002.

Wilby, R. L.: Seasonal forecasting of river flows in the British Isles using North Atlantic pressure patterns, J. Chart. Inst. Water Environ. Manage., 15, 56-63, 2001

Yuan, X., Wood, E. F., and Ma, Z.: A review on climate-modelbased seasonal hydrologic forecasting: physical understanding and system development, WIREs Water, 2, 523-536, 2015. 